\title{
Que sucede con la actualización de la normativa nacio- nal para regular el uso de las radiaciones ionizantes en medicina
}

Carlos Ubeda de la $\mathrm{C}^{*}$, Pablo Soffia $\mathrm{S}^{2}$, Alonso Inzulza $C^{3}$.

1. PhD. Departamento de Tecnología Médica, Facultad de Ciencias de la Salud, Laboratorio de dosimetria personal (LABODOP), Universidad de Tarapacá, Arica, Chile.

2. Médico. Departamento de Imágenes, Facultad de Medicina, Clínica Alemana-Universidad del Desarrollo, Santiago, Chile.

3. Médico. Servicio de Imagenología, Clínica San José. Arica, Chile.

\section{What happens with the update of the national law for the regulation of the use of ionizing radiations in medicine}

\section{Estimado editor}

Cuando se realiza una búsqueda para conocer la normativa nacional que regula el uso de las radiaciones ionizantes en aplicaciones médicas, nos encontramos con cuerpos legales que datan del siglo pasado ${ }^{(1,2)}$. Esta situación resulta al menos paradójica, toda vez que los avances en las tecnologías que utilizan radiaciones ionizantes en medicina han tenido un desarrollo vertiginoso y permanente en los últimos años.

Por otro lado, las aplicaciones clínicas en el diagnóstico y el tratamiento de las enfermedades, han generado que el uso de las radiaciones ionizantes en medicina sean la mayor fuente de exposición a la radiación creada por el ser humano en la actualidad( ${ }^{(3)}$. Es por lo anterior, que el Organismo Internacional de Energía Atómica (OIEA) en conjunto con otras organizaciones vienen promoviendo buenas prácticas para la utilización de estas energías, a través de su programa de Normas de Seguridad desde el año 1958 y, que tiene su última versión el año $2016^{(4)}$. En este sentido, lo que se espera de los países que pertenecen a las Naciones Unidas y por lo tanto al OIEA como es el caso de Chile, es que puedan incorporar cuanto antes estas actualizaciones a su normativa nacional.

Nuestro grupo de trabajo ha venido sistemáticamente aportando evidencia científica desde el año $2007^{(5,6,7,8,9,10)}$ sobre la necesidad de actualizar la normativa nacional, para que se incorporen conceptos tales como: Programas de Garantía de Calidad, Controles de Calidad, Especialistas en Física Médica y Niveles de Referencia para Diagnóstico. Así como también, tener la claridad sobre las magnitudes y unidades sobre la dosimetría que deben conocer los pacientes y trabajadores ${ }^{(11,12)}$.

Finalmente, cabe indicar que vimos con esperanza la consulta pública sobre el nuevo Reglamento de Protección Radiológica propuesto por la división de políticas públicas saludables y promoción de la Subsecretaría de Salud Pública de Chile en el año $2017^{(13)}$, sin embargo, no comprendemos porque aún no se oficializa.

\section{Agradecimientos}

El investigador Carlos Ubeda agradece el apoyo de la Dirección de Investigación de la Universidad de Tarapacá, a través del proyecto de investigación UTA Mayor Nº 7713-18.

\section{Referencias}

1. Reglamento de protección radiológica de instalaciones radiactivas, Decreto Supremo $n^{\circ} 3$ de la República de Chile, 3 de enero de 1985.

2. Reglamento sobre autorizaciones para instalaciones radioactivas o equipos generadores de radiaciones ionizantes, personal que se desempeña en ellas, $u$ opere tales equipos y otras actividades afines, Decreto Supremo $n^{\circ} 133$ de la República de Chile, 22 de mayo de 1984.

3. UNSCEAR. Sources and Effects of lonizing Radiation. Volume I: Sources: Report to the General Assembly, Scientific Annexes A and B. UNSCEAR 2008 Report. United Nations Scientific Committee on the Effects of Atomic Radiation. United Nations sales publication E.10.XI.3. United Nations, New York, 2010.

4. Disponible en: https://servei.org/wp-content/uploads/P1578_S_web.pdf (Accesado el 09/feb/2020) 
5. Ubeda C, Leyton F, Galaz S, Oyarzún C, Inzulza A. Garantía de calidad y protección radiológica en las exposiciones médicas en europa: un ejemplo a seguir. Rev Chil Radiol 2007; 13(4): 208-212.

6. Ubeda C, Miranda P, Vaño E, Nocetti D. Protección radiológica en cardiología intervencionista Pediátrica. Avances y desafíos para Chile. Rev Chil Car 2013; 32(3): 223-229.

7. Miranda P, Ubeda C, Vaño E, Nocetti D. Recomendaciones para mejorar la seguridad radiológica durante los procedimientos de intervencionismo cardiológico. Rev Chil Car 2014; 33(1): 44-50.

8. Ubeda C. Investigación sobre la protección radiológica en procedimientos radiológicos dentales. Cuanto hay en Chile. Int J Odontostomat 2018; 12(2): 91-92.

9. UbedaC, Nocetti D, Aragón M. Seguridad y Protección Radiológica en Procedimientos Imagenológicos Den- tales. Int J Odontostomat 2018; 12(3): 246-251.

10. Ubeda C, Vaño E, Ruiz Cruces R, Soffia P, Fabri D. Niveles de referencia para diagnóstico: Una herramienta efectiva para la protección radiológica de pacientes. Rev Chil Radiol 2019; 25(1): 19-25.

11. Ubeda C, Nocetti D, Alarcón R, Inzulza A, Calcagno S, Castro $\mathrm{M}$ et al. Magnitudes y unidades para dosimetría a pacientes en radiodiagnóstico e intervencionismo. Rev Chil Radiol 2015; 21(3): 94-99.

12. Ubeda C, Nocetti D, Inzulza A, Oyarzún C, Alarcón R. Magnitudes y unidades para dosimetría del personal ocupacionalmente expuesto en radiodiagnóstico e intervencionismo. Rev Chil Radiol 2018; 24(1): 5-11.

13. Disponible en: https://www.minsal.cl/wp-content/ uploads/2017/01/Consulta-p\%C3\%BAblica-Reglamento-de-Protecci\%C3\%B3n-Radiol\%C3\%B3gica. pdf (Accesado el 19/feb/2020).

Ubeda $C$, et al. Que sucede con la actualización de la normativa nacional para regular el uso de las radiaciones ionizantes en medicina. Rev Chil Radiol 2020; 26(1): 06-07.

*Correo electrónico: Carlos Ubeda de la Cerda / carlos.ubeda.uta@gmail.com.

Trabajo enviado el 03 marzo de 2020. Aceptado para publicación el 17 de marzo de 2020. 